\title{
Why Addressing Gender Is Foundational
}

Legally perpetuated gender inequality has been pervasive globally for millennia. Women have been excluded by law from property ownership, professions, and political participation. Only for slightly over a century have women been allowed to vote-finally gaining this fundamental right first in 1893 in New Zealand and only in 2011 in Saudi Arabia. ${ }^{1}$ Women's social and economic rights, and their full realization, lag far behind men's. In all countries but one, the average woman still earns less than the average man, ${ }^{2} 104$ countries have legal barriers to women's employment in specific jobs, ${ }^{3}$ and one-third of the world's countries lack laws against workplace sexual harassment. ${ }^{4}$ In every society, gender-based violence continues to inhibit women's ability to move freely through the world and exercise other fundamental rights and devastating loopholes undermine rape prosecutions in far too many nations. ${ }^{5}$

Gender-based discrimination remains the form of discrimination that affects the most individuals globally, impacting nearly every household. Gender discrimination cuts across social class, race/ethnicity, and religion; leaves marginalized groups of women further behind; and leaves women in nearly all groups less likely to have an equal voice, decision-making roles, or opportunities for equal resources.

To address inequality, we must first understand where and how discrimination occurs, as well as the extent to which constitutions and laws can address each type of discrimination. In the case of gender, inequality is fueled by 
- Discrimination embedded in laws and government policies. Examples include laws that historically prohibited women from voting, continue to bar women from certain professions, or limit women's freedom of movement. Laws that differentiate on the basis of sex, in ways that perpetuate inequity rather than redress past inequality, embody and further discrimination. In $80 \%$ of countries, inequalities in labor/social security laws limit whether all people regardless of sex or gender have equal opportunities to perform the same jobs, work under the same conditions, take paid leave for infant care, or retire at the same age. ${ }^{6}$

- Governments' failure to prohibit common discriminatory practices. For example, when governments neglect to legally prohibit workplace sexual harassment or gender discrimination in employment, they facilitate abuse, unequal pay, and disparities in hiring and firing. One-quarter of countries do not explicitly prohibit gender discrimination in either hiring or terminations, and nearly half fail to explicitly guarantee women equal pay for work of equal value. ${ }^{7}$ Similarly, nearly half fail to prohibit discrimination in decisions regarding promotion or advancement. ${ }^{8}$

- Policies and rules of private institutions that create unequal opportunities in education, civic participation, and other spheres. Private institutions that exclude individuals based on gender, including some schools and social/political organizations, are engaging in direct discrimination. Such private policies' impact is magnified when these institutions provide entry points for opportunities to participate or assume leadership roles in education, the economy, government, or politics.

- Individual actions, taken on behalf of institutions, that are systematically discriminatory-even when policies are not. Extensive evidence has demonstrated that individual action can increase disparities. For example, studies in which prospective employers receive resumes that are identical aside from applicants' names have revealed systematic gender discrimination; men receive more interview invitations than women. ${ }^{9}$ While institutions' advertisements may not specify that jobs are restricted on the basis of gender, individuals' implementation of searches can be heavily biased.

- Laws that regulate interpersonal relations in ways that limit equal rights and shared decision-making. Examples include laws that treat men and women differently with respect to rights in marriage or divorce, the ability to make decisions on their children's behalf, or the ability to confer citizenship to family members. ${ }^{10}$

Sustainable change requires challenging inequalities in constitutional rights, laws and policies, programs and services, and norms. While change at every level of government is greatly needed, constitutions often provide the strongest foundation for countering discrimination and unequal treatment of men and women by governments, public institutions, and laws governing civic space. Depending on the details of their provisions and implementation, constitutions can also reduce discrimination in private institutions and advance equality in private relations. 


\section{CONSTITUTIONS' ABILITY TO ADDRESS LAWS AND POLICIES FUELING GENDER INEQUALITY}

Around the world, both individual women and civil society groups have employed their constitutions' equal rights protections to challenge the types of discrimination described above. These efforts have yielded remarkable victories, including court decisions affirming women's right to confer citizenship in Botswana, ending a prohibition on married women's property ownership in Swaziland, and invalidating the exclusion of female applicants for a position in Kuwait's Justice Ministry.

In Zimbabwe and Nepal, women have leveraged their constitutions over the past two decades to challenge some of the discrimination women face at the intersection of their public and private lives. From laws permitting girls to be married as children to legal exceptions for marital rape, these cases reveal the consequences of unequal treatment by governments for both public opportunities and relationships within families. Further, the courts' demonstrated capacity to address these different types of discrimination underscores the role constitutions can play in dismantling gender inequality in all spheres, provided they are well designed.

\section{Zimbabwe: Addressing Gender Discrimination Embedded in Child Marriage Legislation}

In 2013, 95\% of Zimbabwean voters approved a new constitution containing strengthened provisions on gender equality, including overall equal rights guarantees, specific protections of women's social and economic rights, and recognition of "gender equality" as a founding principle. ${ }^{12} \mathrm{~A}$ recent case on child marriage illustrates how these provisions have provided tools for changing laws and challenging private decisions that have discriminatory impacts.

As of 2014, the rate of child marriage among girls in Zimbabwe was $34 \% .^{13}$ That year, two of these girls, Loveness Mudzuru and Ruvimbo Tsopodzi, now young women, challenged Zimbabwe's minimum marriage age law, which permitted girls to be married at 16-two years earlier than boys. The disparity, the women argued, amounted to discrimination violating Article 81 of the constitution, which established that "every boy and girl under the age of eighteen years, has the right to equal treatment before the law."

The Constitutional Court agreed, citing both Article 81 and Zimbabwe's commitments to gender equality under the U.N. Convention on the Elimination of All forms of Discrimination Against Women (CEDAW) and the U.N. Convention on the Rights of the Child. Tendai Biti, the young women's lawyer, remarked on the victory's significance: "Parliament should have done this many years ago. They had over 36 years to do it; they did not do it. So it has taken a bold decision from a bold court to do this." ${ }^{14}$ 
While changing laws is only the first step in eliminating child marriage-and while the age of marriage law has yet to be amended as of this writing-Zimbabwe's example shows how establishing gender equality as a fundamental constitutional principle can provide the foundation for ending discriminatory legislation, even when the legislature has been slow to act. Since the Zimbabwe case, a Tanzanian high court delivered a similar ruling declaring its child marriage legislation, and specifically legal disparities in the minimum age, unconstitutional. ${ }^{15}$

\section{Nepal: Reforming Laws to Support Greater Equality in Private Relationships}

As illustrated by Zimbabwe, constitutions have proven to be critical tools in countering discriminatory legislation, including unequal child marriage laws, which undermine girls' opportunities and facilitate relationships that are often marked by abuse. ${ }^{16}$ Yet legal inequalities can persist even when both partners enter into marriage as fully consenting adults.

Although legislation prohibiting sexual violence has strengthened in recent decades, many countries' laws provide inadequate protection against rape by people known to the victims, in general, and marital rape in particular. A 2017 Equality Now report found that marital rape was expressly legal in $12 \%$ of the countries studied. ${ }^{17}$ Starkly underreported and rarely prosecuted, marital rape remains a form of domestic violence that has too long left women with little legal recourse.

In Nepal, the Forum for Women in Law and Development (FWLD), a national NGO, challenged the exception for marital rape on the basis of women's equal rights in the constitution. In its decision, Nepal's Supreme Court cited not only the constitution's equality guarantee but also Nepal's CEDAW commitments, specifically referencing CEDAW's expansive definition of sex discrimination: "any distinction, exclusion or restriction made on the basis of sex which has the effect or purpose of impairing or nullifying the recognition, enjoyment or exercise by women, irrespective of their marital status, on a basis of equality of men and women, of human rights and fundamental freedoms in the political, economic, social, culture, civil or any other field." Moreover, the Court refuted the state's claim that a consent requirement in marriage was incompatible with Hinduism, or that "marriage is a permanent consent expressed to have sexual relations." ${ }^{18}$ Drawing on both the constitution and Nepal's international commitments, the Court pronounced that " $\mathrm{t}]$ here is no justification in differentiating between women who are wives and other women," and called on the legislature to "define marital rape ... as a criminal offence." ${ }^{\prime 9}$

Advocates recognized the victory's importance, but acknowledged that it was just one of the steps needed to end violence against women. According to Sapana Pradhan Malla, FWLD president and a lawyer who worked on the case, "[r]ecognizing rape within marriage as a crime is the first step. The second step is to amend the law and to get it passed in parliament. Third, enforcement and 
awareness measures have to be put in place to create an environment for victims to come forward." ${ }^{20}$

The second step was soon realized. In 2006, the Nepalese Parliament passed the Gender Equality Act, which criminalized marital rape. Yet when women began using the law, Pradhan Malla noticed that their husbands received remarkably light sentences compared to others found guilty of rape. ${ }^{21}$ Through another case in 2008, she challenged the disparity, which had actually been written into the Gender Equality Act-and won. The Court held that "there is no rationality in differentiating between marital and non-marital rape," effectively abolishing distinctions in punishment for different types of perpetrators. ${ }^{22}$

While challenges continue in order to ensure that new rape laws are implemented and that women can access the supports needed to leave violent relationships, FWLD's work in Nepal shows how constitutional equality guarantees can help dismantle discriminatory legislation and support women's equal rights in both the public and private spheres. More recently, FWLD has taken on gender inequalities in inheritance law.

Yet there have also been setbacks, including a new constitution, enacted in 2015, that prohibits women from passing on citizenship to their children independently of men. ${ }^{23}$ Women's groups throughout Nepal have vowed to continue pushing for change-including a constitutional amendment-to ensure that the principle of gender equality is fully realized. ${ }^{24}$

\section{ADVANCING GENDER EQUALITY IN CONSTITUTIONS}

As demonstrated in Nepal, Zimbabwe, and numerous other countries, guaranteeing gender equality in constitutions can have, and has had, significant tangible impacts-from strengthening women's protection from violence to removing barriers to women's employment. And importantly, these reforms' benefits are not limited to women. Removing obstacles to women's full participation in society creates gains that extend across all people, families, communities, and entire economies. As discussed in depth toward the end of this chapter, using the law to counter gender stereotypes can broaden opportunities for everyone. So how many countries enshrine this value in their fundamental documents? And are equal rights provisions designed such that they can reach gender discrimination in the public sphere, private institutions, and the family alike?

\section{Building a Universal Foundation: Gender Equality Provisions Governing State Action}

The overwhelming majority of constitutions (85\%) explicitly guarantee gender equality, most often by prohibiting formal discrimination by the state and/or guaranteeing equal rights regardless of sex or gender (see Map 5). For example, Spain's constitution provides that "Spaniards are equal before the law and may not in any 


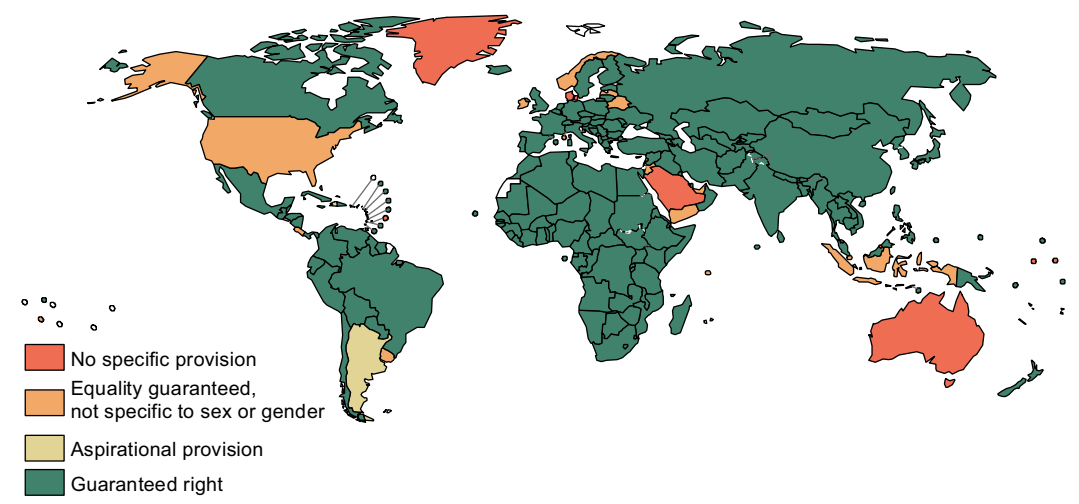

MAP 5. Does the constitution explicitly guarantee equality or nondiscrimination across sex and/or gender?

way be discriminated against on account of ... sex." ${ }^{25}$ Similarly, Eritrea's constitution provides: "1. All persons are equal under the law. 2. No person may be discriminated against on account of ... gender." ${ }^{26}$

Additionally, 5\% of constitutions address indirect discrimination on the basis of sex, providing a tool for challenging laws and policies that are not explicitly discriminatory but have discriminatory effects. For example, Cyprus's constitution provides: "Every person shall enjoy all the rights and liberties provided for in this Constitution without any direct or indirect discrimination against any person on the ground of ... sex." ${ }^{27}$

Gender equality has figured centrally in a range of recent constitutional reform processes. For example, Tunisia's 2014 constitution, adopted three years postrevolution, guaranteed equal rights for men and women-in a first for both the country and the region. "This article is a revolution in itself," said Lobna Jeribi, a scientist and member of the constituent assembly created to chart the country's path forward. "It's a big, historic step, not only for Tunisian women." ${ }^{28}$

When the constitution passed, similar reactions reverberated throughout the streets, social media, and the legislature itself, where the gender equality provisions had been hotly debated. For assembly vice president Meherzia Labidi, who had campaigned for the new protection despite resistance in the religious political party she represented, the gender equality provision was "one of the articles in the constitution that I am most proud of." ${ }^{29}$ The gender equality articles also included a requirement to work toward gender parity in elected bodies..$^{30}$ In the years since, more equal political representation has followed. Thanks to a 2014 local elections law establishing more specific measures to advance gender parity, Tunisia’s 2018 municipal elections marked the country's first election with equal numbers of male and female candidates; women ultimately won $47.7 \%$ of seats. ${ }^{31}$

All constitutions adopted in 2000-2017, including Tunisia's, include explicit gender equality guarantees-a notable change from the constitutions of a century 


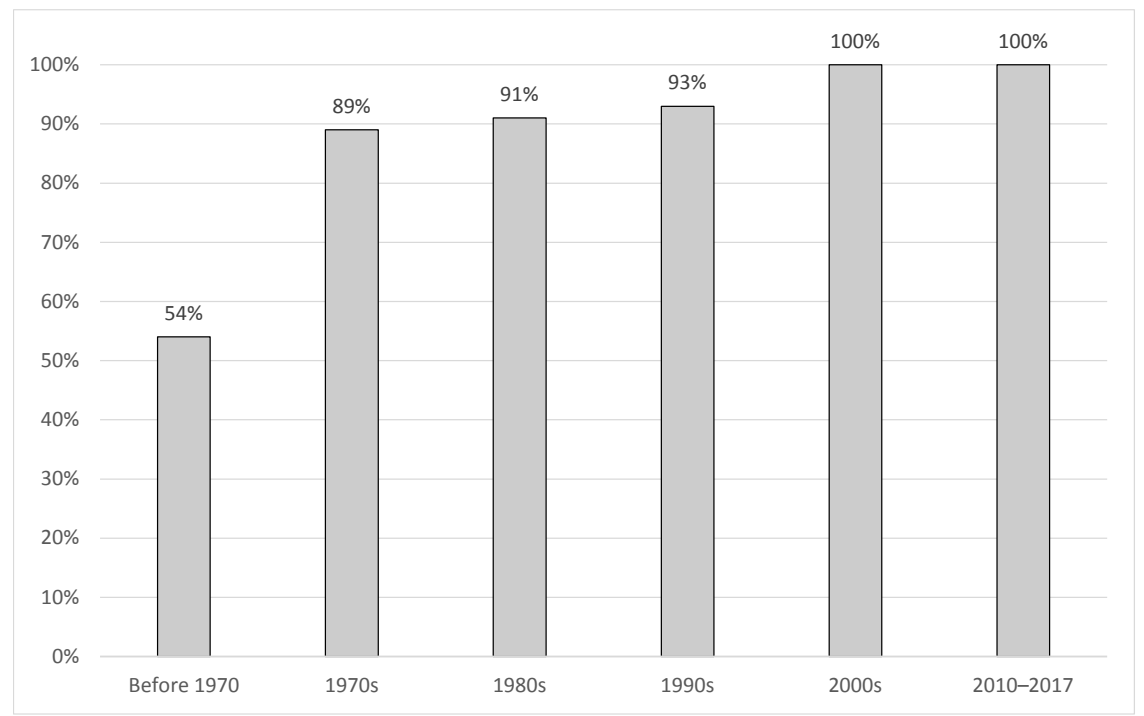

FIGURE 3. Explicit constitutional guarantee of equality or nondiscrimination across sex and/or gender by year of constitutional adoption

ago (see Figure 3). Although only a first step toward realizing gender equality in practice, such guarantees signal a critical commitment to protecting equal rights and provide mechanisms for challenging discriminatory barriers.

\section{Reducing Discrimination in the Private Sector}

Today, private institutions are increasingly playing a role in providing traditionally public services, including healthcare and education, that are essential to the fulfillment of other fundamental human rights..$^{32}$ If private institutions providing these services are exempt from constitutional restraints, then "the protective umbrella of the concept of a private sphere prevents them from being held accountable for their action," drastically weakening guarantees of fundamental rights and nondiscrimination. ${ }^{33}$

Moreover, private institutions play larger roles than ever in countries' economies, directly impacting the ability of individuals to earn income and meet basic needs. Consequently, private-sector discrimination is a critical concern for the well-being of all groups included in this book. Gender discrimination in privatesector workplaces-whether during hiring processes or in decisions about pay and promotions-can starkly undermine women's ability to support themselves and exercise other fundamental rights.

While prohibiting direct discrimination by state actors is essential-and the original role of constitutional equal rights clauses-these protections reach only a fraction of the discrimination that affects women and girls, as well as other 
marginalized groups, globally. Discrimination in the private sphere, whether by service providers, employers, or landlords, can profoundly affect women's livelihoods and exercise of other rights. Can constitutions effectively address these forms of discrimination?

\section{Zimbabwe: Pregnancy Discrimination in Private Schools}

In Zimbabwe, a 1999 case illustrates the importance of addressing discrimination by private service providers - as well as the limitations of constitutions that do not clearly articulate their ability to reach these institutions.

Twenty-one-year-old Enita Mandizvidza had just gotten married and was preparing to finish her third and final year at Morgenster Teachers' Training College in Masvingo, Zimbabwe. But when Mandizvidza got pregnant, the school's principal declared that she would be expelled as a consequence. ${ }^{34}$ She would no longer be able to take her fall exams and would have to put her career goals on hold.

Mandizvidza's expulsion hinged on a contract that students were required to sign upon enrolling at the college, a private school operated by the Reformed Church. ${ }^{35}$ One provision read: "I understand that I will be withdrawn from the course when I fall pregnant or am involved in causing the pregnancy of another student or pupil." ${ }^{36}$ Like other new students, Mandizvidza had signed. Yet when it became the basis for her expulsion, she questioned how the contract could be compatible with gender equality.

Shortly after being forced to sign a letter of resignation, Mandizvidza took her case to Zimbabwe's High Court, where she challenged the school's action as unconstitutional gender discrimination-and prevailed. ${ }^{37}$ However, the school appealed, arguing that because it was a private institution, the constitution's protections against discrimination did not apply.

In 2002, the Supreme Court ruled on the case. As the Court explained, the constitution then in place explicitly protected only against discrimination by a "public authority." In some cases, the Court noted, this could include private institutions providing traditionally public services like education-but only where the state exercised some control over their operations. However, the Court found that was not the case for Mandizvidza's school: although the government provided some funding, it was "not responsible for, nor $\mathrm{d}[\mathrm{id}]$ it have control of, the education at the college."

Nevertheless, the Court cited precedents establishing its authority to declare a contract "contrary to public policy." Using this legal basis, the Supreme Court invalidated the contract, finding that its expulsion provision had broad consequences and created double standards for male and female students: "It punishes the married woman who falls pregnant. It does not punish the male student who has extra-marital sex with a non-student, even if she becomes pregnant as a consequence." ${ }^{8}$ Through this contract law rationale, Mandizvidza's case was ultimately resolved in her favor. At the same time, the Court noted that its 
authority to void contracts could only "be exercised sparingly and only in the clearest of cases."

Ensuring that constitutional protections can reach discrimination within private education and employment is critical for the full, consistent realization of equal rights. Moreover, cases from other countries indicate that pregnancy discrimination - a form of gender discrimination discussed in more detail toward the end of this chapter-remains common, particularly in schools and workplaces. ${ }^{39}$

Across Contexts: Constitutional Approaches to Reaching Private-Sector Gender Discrimination

The application of constitutional rights to private actors is an emerging issue worldwide. As understandings of constitutions and the "public/private divide" shift, courts are increasingly applying constitutional values to cases between private parties even when constitutional provisions are not directly applicable against private actors. ${ }^{40}$

For example, Colombia's constitution broadly provides that "[w]omen cannot be subjected to any type of discrimination," which the Constitutional Court has interpreted to prohibit discrimination by both the state and private employers. This interpretation has yielded rulings expanding protection against private sector pregnancy discrimination and affirming a pilot's right to health coverage for her miscarriage. ${ }^{41}$ The broad scope of Colombia's gender discrimination provision is further bolstered by the acción de tutela, a unique legal mechanism that allows individuals to approach the Constitutional Court with a claim against a private party that is directly threatening their fundamental rights, provided they are in a subordinate position to the defendant and have no other remedies..$^{42}$ (We discuss the tutela in more detail in later chapters.)

Countries have also already shown that constitutions can more directly prohibit discrimination in private workplaces. For example, Bolivia's constitution declares: "The State shall promote the incorporation of women into the workforce and shall guarantee them the same remuneration as men for work of equal value, both in the public and private arena." 43

In other countries, constitutions have begun to address discrimination by private actors beyond the workplace. For example, Chad's constitution provides: “The state assures to all equality before the law, without distinction of . . s sex . . . . It has the duty to see to the elimination of all forms of discrimination with regard to women and to assure the protection of their rights in all areas of private and public life." 44

Likewise, Equatorial Guinea's constitution provides that every citizen enjoys equality before the law, further clarifying that " $[\mathrm{t}]$ he woman, whatever her civil status may be, has equal rights and opportunities as the man in all the orders of public, private, and family life, [and] in civil, political, economic, social, and cultural [life]." 45 


\section{Equal Rights within the Family and Reproductive Health}

One area of private life that deserves special attention is the family. As the introductory cases illustrated, laws and policies establish legal rights within marriages and other partnerships. These include the ability to enter and exit marriage and rights within marriage, as individuals and with respect to pregnancy and children. As a matter of justice, these rules must treat all parties equally and fairly. The impacts of unfair rules on individual women, their children, and broader society can be profound.

Constitutional provisions establishing equal rights in the family can provide a foundation for overturning discriminatory family laws and marital practices. For example, Uganda's Supreme Court ruled in 2015 that a customary law requirement that women refund their "bride price" upon divorce was unconstitutional. In Uganda, a bride price, similar to a dowry, is a pre-marriage transfer of livestock or other assets from the groom to the bride's family. In 2007, Mifumi, a Ugandabased international women's rights group, initiated a challenge to the bride price. ${ }^{46}$ In addition to arguing that the bride price itself was discriminatory and treated women like property, Mifumi alleged that the requirement that it be refunded upon a marriage's dissolution compelled women to stay in violent relationshipsan assertion supported by research and women's personal accounts. ${ }^{47}$

When the case finally reached the Supreme Court in 2015, Justice Jotham Tumwesigye ruled that "the custom and practice of demand for refund of bride price after the break down of a customary marriage is unconstitutional as it violates Article $31(1)(\mathrm{b})$ of the Constitution," ${ }^{48}$ which provides that men and women "are entitled to equal rights in marriage, during marriage and at its dissolution." While the Court stopped short of declaring the bride price itself unconstitutional, women's rights advocates viewed the ruling on refundability as a major blow against the practice. ${ }^{49}$

\section{Equal Rights in the Family: Current Constitutional Approaches}

Globally, only one-quarter of constitutions guarantee equal rights within or while entering and exiting marriage (see Map 6). Just 6\% comprehensively protect equality at each stage: entering, exiting, and within marriage. Armenia's constitution, for instance, provides that men and women "are entitled to equal rights as to marriage, during marriage and divorce," while Ecuador establishes that marriage is based on "equality of rights, obligations and legal capacity." ${ }^{\circ}$

\section{Reproductive Rights in Constitutions}

Finally, constitutional protections for women's reproductive rights both are vital in themselves and can importantly complement protections of women's equal rights as individuals and within relationships, as family planning influences women's broader realization of their rights. Insufficient access to reproductive healthcare 


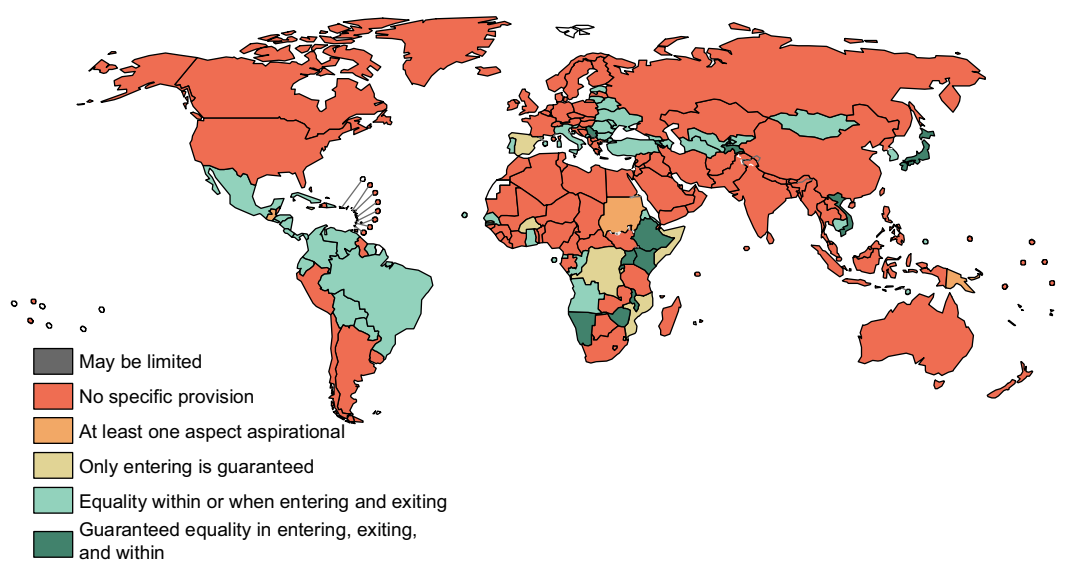

MAP 6. Does the constitution explicitly protect women's right to equality in marriage in all aspects including entering, exiting, and within marriage?

imperils many women's health, autonomy, and educational and economic prospects. Constitutions can provide stronger protections both by explicitly establishing equal rights to health regardless of sex or gender, and by specifically referencing reproductive and maternal health. For example, Nepal's 2015 constitution establishes: "Every woman shall have the right to safe motherhood and reproductive health," and the Supreme Court's interpretation of a similar provision in the 2007 interim constitution encompassed a broad range of reproductive and maternal health rights. ${ }^{51}$

In some countries, these provisions have provided bases for challenging legislation restricting reproductive rights. For example, in 2006, Colombia's Constitutional Court ruled that the country's complete ban on abortion violated women's constitutional right to health, and decriminalized the termination of pregnancies in limited circumstances. In so doing, the Court held that the protection of prenatal life, while a constitutional value, could not take "absolute privilege" over women's fundamental rights to health, dignity, and autonomy.52 While advocates continue to push for more comprehensive reproductive rights in Colombia and throughout Latin America, the 2006 ruling represented a significant step forward..$^{53}$

The rights to physical health, mental health, and bodily autonomy are fundamental, universal human rights. ${ }^{54}$ Ensuring women are the decision-makers when it comes to their own reproductive health is critical to both protecting these rights and laying a foundation for gender equality. While few constitutions currently address reproductive rights in detail, at a time when up to $13.2 \%$ of maternal deaths each year are attributable to unsafe abortion, ${ }^{55}$ strengthening legal protections for women's decision-making regarding their own medical care should be a priority for equal rights and public health. 


\section{ADVANCING GENDER EQUALITY WITHOUT}

\section{CLEAR EQUAL RIGHTS}

Progress on women's equal rights in constitutions over the past century has been remarkable-yet $15 \%$ of countries, home to 404 million women, have yet to include specific language in their constitutions. ${ }^{56}$ In these countries, identifying other strategies to advance women's rights, while continuing to push for clear protections in the text, can be important for accelerating progress. The United States provides an example.

\section{United States: A Long Road to Women's Equal Rights}

The U.S. guarantees equal rights in broad language, but not explicitly on the basis of sex or gender. According to the Fourteenth Amendment, ratified in 1868, "[n]o State shall ... deprive any person of life, liberty, or property, without due process of law; nor deny to any person within its jurisdiction the equal protection of the laws." In the absence of explicit text, eliciting constitutional protections of women's rights has been an uphill, decades-long battle premised on incremental victories at the Supreme Court.

While the Nineteenth Amendment extended the right to vote to American women in 1920, it was not until a series of cases in the 1970s, many argued by future Supreme Court Justice Ruth Bader Ginsburg, that the constitution's scope of protection for gender equality more broadly took shape. Some of the first cases strategically approached the subject from the perspective of a disadvantaged man, such as the widowed husband who could not access survivor benefits without proving his financial dependence on his late wife, whereas hers was presumed. ${ }^{57}$ In fact, male plaintiffs brought over two-thirds of the gender equality cases argued before the Supreme Court between 1971 and 1984, the key period during which the Court's gender equality jurisprudence developed. ${ }^{58}$

Yet although Justice Ginsburg's focus on male plaintiffs may have been more strategic than ideological, some early discrimination cases following this model clearly illustrated how gender stereotypes can limit opportunities for both men and women. For example, in a 1982 case, a male applicant to a women-only nursing school established in 1884 challenged the admissions criteria as violating the Equal Protection Clause. Although the school claimed that limiting admission to women constituted affirmative action, the Court, in a decision authored by its first female justice, Sandra Day O'Connor, disagreed, especially since the gender restriction "tends to perpetuate the stereotyped view of nursing as an exclusively women's job." ${ }^{59}$ Despite maintaining the name "Mississippi University for Women," men now comprise nearly $10 \%$ of the university's nursing school students. ${ }^{60}$

Over time, these cases emanating from the constitution's general equality provision - the Equal Protection Clause-established a precedent holding that 


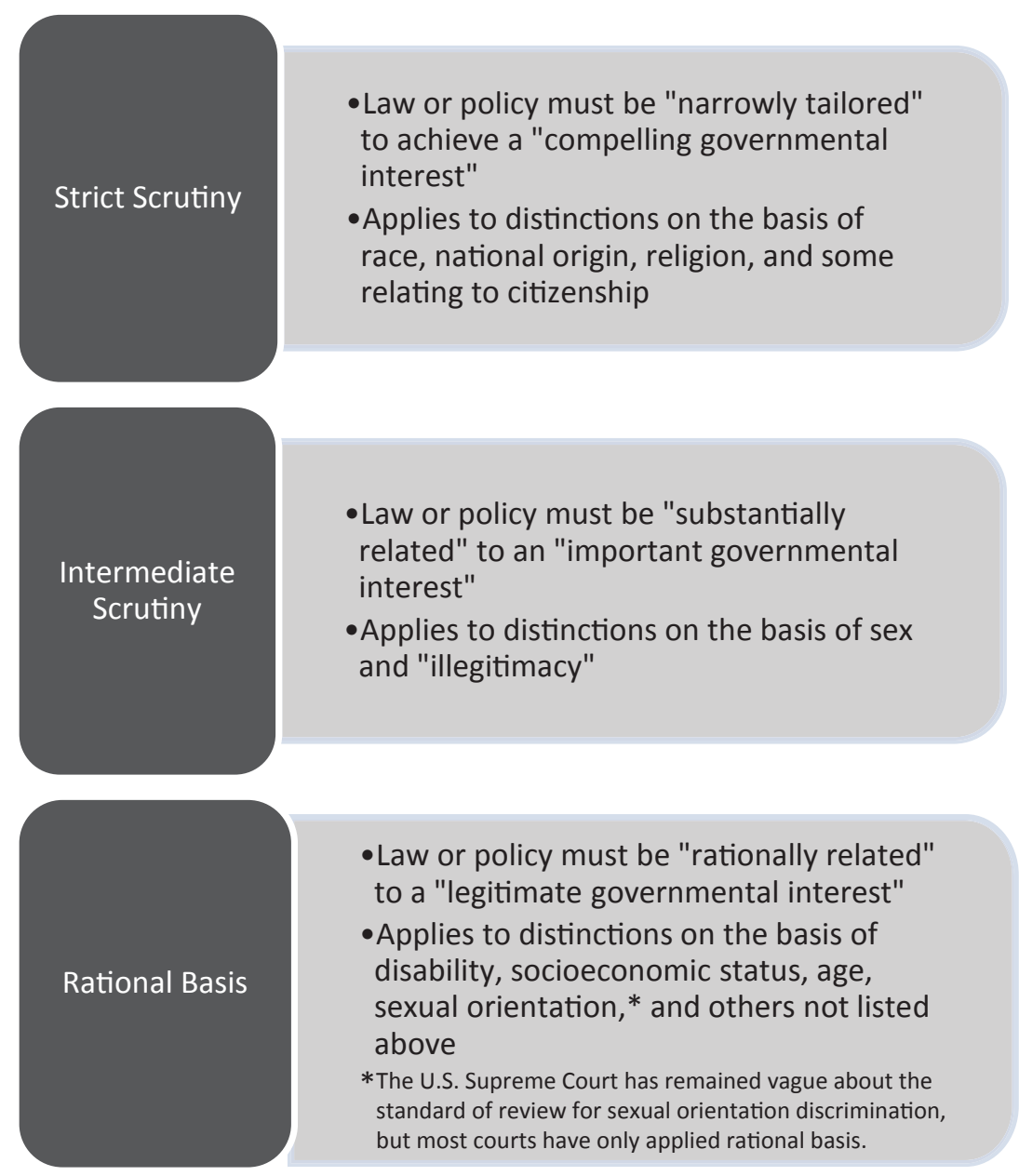

FIGURE 4. Equal Protection Clause of the Fourteenth Amendment: current standards of review.

discrimination against women was unconstitutional unless the government could prove the discriminatory law was "substantially related" to an "important government interest." This "intermediate scrutiny" assessment of constitutionality would prove unique, falling between the "strict scrutiny" test applied to racial classifications and the "rational basis" test used to assess restrictions on rights for groups that do not currently receive special protection under the law (see Figure 4).

While the victories achieved for women under the Equal Protection Clause have been critical, the path toward their realization has been needlessly tortuous and even controversial. ${ }^{61}$ 


\section{Older Constitutions and Newer Rights}

As a practical matter, one reason the U.S. Constitution does not include a gender equality guarantee is that in addition to being one of the world's oldest constitutions, it is particularly difficult to amend; although the U.S. Congress actually voted to adopt an Equal Rights Amendment (ERA) in the early 1970s, by 1982, it had failed to attain the required ratification by at least 38 of the 50 states. Recently, however, a revived movement to ratify the ERA has achieved some important victories: in 2017 , Nevada became the 36 th state to ratify the ERA, followed by Illinois in 2018. While legal scholars debate the feasibility of enacting the ERA after the initial deadline, some argue that the U.S. is just one state vote away from a constitutional amendment generations in the making.

As this example suggests, while the difficulty of amending most constitutions makes them especially powerful instruments for establishing enduring protections of rights, it also creates hurdles to enacting new equality protections that were not included initially. Still, some countries with older constitutions have successfully adopted amendments to protect women's rights and keep up with global norms. For example, Luxembourg amended its 1868 constitution in 2006 to affirm that " $[\mathrm{w}]$ omen and men are equal in rights and duties," and that "[t]he State must actively promote the elimination of any existing obstacles to equality between women and men." ${ }^{2}$

\section{DESIGNING PROTECTIONS FOR WOMEN'S \\ EQUAL RIGHTS: IMPORTANT GAPS AND MORE DIFFICULT QUESTIONS}

The fact that $85 \%$ of constitutions now include language specifically protecting women's equal rights attests that striving for gender equality has become a global norm. Nevertheless, the global extent of disparities indicates that existing protections have not sufficed to inaugurate a new era for equal rights and opportunities.

In some countries, courts' narrow interpretations of gender equality provisions have limited their potential for impact. For example, "sex discrimination" has not always been interpreted to fully cover pregnancy discrimination; especially given how few constitutions currently address indirect gender discrimination, these narrow readings have significant potential consequences. Other countries, attempting to recognize the disproportionate role women continue to play in caregiving, have tacitly endorsed unequal gender norms by treating gendered divisions of household labor as natural.

Further, historically, both constitutional texts and case law have often taken narrow, binary approaches to sex and gender, or have framed gender equality solely in terms of women. To advance transformative change, constitutions and the people who enforce them must take a broad view of gender equality that acknowledges 
the many ways restrictive gender norms not only limit women's opportunities, but also foster discrimination against men who do not adhere to narrow expectations about masculinity, as well as sex and gender minorities.

The way that constitutions are drafted can help ensure courts and legislatures address gender equality more effectively and comprehensively. Below, we examine a few key choices likely to make a difference.

\section{Questions of Language: Sex vs. Gender}

One choice for constitution drafters is whether to prohibit discrimination on the basis of gender or of sex. Put simply, sex refers to biological differences, while gender refers to the roles, responsibilities, and characteristics typically associated with being male or female in a particular cultural context. ${ }^{63}$ Gender norms are the unspoken "rules" about what behaviors and attributes are deemed acceptable and valuable for men and women, respectively. ${ }^{64}$

Evidence shows that while sex discrimination remains rampant, discrimination against people who do not align with gender-normative expectations is similarly widespread and damaging. For example, in workplaces, while "assertive" behavior by men is generally viewed favorably, assertive women are viewed as less competent. ${ }^{65}$ Meanwhile, men who are perceived as more sensitive or "nurturing" - characteristics aligning with feminine rather than masculine stereotypes-are viewed as lacking leadership skills. ${ }^{66}$

These expectations also shape individuals' access to employment opportunities. Violating unspoken "rules" about gender can lead to backlash and discrimination in hiring. ${ }^{67}$ Additionally, widespread perceptions of certain jobs as traditionally "male" or "female" can exacerbate occupational gender segregation, and discourage people from entering fields where they would be a distinct minority. For example, on average, just $6 \%$ of the world's early childhood education teachers are male. ${ }^{68}$

Addressing both sex and gender is one way that constitutions can acknowledge how stereotypes and culturally defined expectations about what it means to be a man or a woman can contribute to discrimination, and limit opportunities for all people at home, at work, and within the political sphere.

Among countries guaranteeing equal rights, most list "sex" as the relevant protected category in their equality provisions; a smaller number use "gender." In a few countries, such as Fiji, Guyana, South Africa, and Zimbabwe, both "sex" and "gender" are included as prohibited grounds of discrimination. (In chapter 6, we look separately at protections for "gender identity.")

Countries also vary in whether they use a "symmetrical" approach or specifically frame women's equal rights in relation to men's. Five countries protect gender equality only within the framework of ensuring women's rights. For example, France's constitution provides: "The law guarantees women equal rights to those of 
men in all spheres." ${ }^{69}$ Likewise, China's constitution states: "Women in the People's Republic of China enjoy equal rights with men in all spheres of life, in political, economic, cultural, social and family life." 70 This "asymmetrical" approach, while importantly protecting women's basic rights, establishes men's rights as the baseline, rather than recognizing and guarding against the range of ways that gender stereotypes can hurt women, men, and gender minorities alike. ${ }^{71}$

Ultimately, fulfilling equal rights requires addressing both sex and gender discrimination, and dismantling discriminatory norms that limit opportunities for everyone. However, doing so may require different approaches in different contexts. While a small subset of constitutions now directly address both sex and gender in the text, this strategy may be less straightforward in some countries; in Arabic, the words "sex" and "gender" are typically the same (سن ج), which helps explain why different English translations of Arabic constitutions sometimes use different terms for the same article. ${ }^{72}$ In Bahasa, the national language of Malaysia, there is no word for "gender." ${ }^{33}$ Further, for the many countries whose constitutions prohibit only "sex" discrimination, the odds of passing an amendment to add "gender" may be quite low, given the general procedural barriers to constitutional amendment and the political mobilization required.

Within courts, justices have not consistently held that protections against sex discrimination extend to laws or policies prescribing adherence to gendered expectations, including dress- or appearance-related conventions. ${ }^{74}$ For example, in 1977, the U.K. Employment Appeal Tribunal held that a bookshop's prohibition of female employees wearing pants did not amount to sex discrimination; ${ }^{75}$ two decades later, it confirmed this precedent in ruling against a male delicatessen worker who was fired for having a ponytail, when no such restriction applied to female employees. ${ }^{76}$ Likewise, in 1991, Germany's Constitutional Court ruled that an employer's prohibition on men wearing earrings did not amount to sex discrimination. ${ }^{77}$

Protections against gender discrimination are important for providing legal recourse for discrimination based on gendered expectations not only about appearance, but also about behavior. As noted earlier, studies have shown that women and men are evaluated differently based on the same qualities, depending on whether those qualities align with or diverge from gendered expectations about demeanor. Prohibiting sex discrimination alone may be insufficient to address these forms of conscious and unconscious bias. For example, if a mining company consistently prefers male over female candidates, but refuses to hire more soft-spoken or seemingly "gentle" men who are nevertheless well qualified for the job, then both sex discrimination and gender discrimination are taking place. Wherever possible, enacting more comprehensive provisions would strengthen the protective potential of constitutional text and other laws. Beyond improving constitutions through explicit protections, urging courts to adopt an expansive interpretation of "sex discrimination" encompassing both physical traits 
and gendered social expectations is essential to comprehensive protections from discrimination. ${ }^{78}$ Ultimately, the more comprehensive the text, the better the odds it will consistently provide protection of equal rights for all people.

\section{Questions of Impact: Accounting for Real Differences without Sanctioning Discrimination}

A critical question is how to design constitutions enabling courts to address discrimination based on genuine intergroup differences, such as women's unique experiences with pregnancy, without opening the door for wider discrimination.

There is great strength in explicitly prohibiting discrimination on the basis of pregnancy and marital or family status, as well as gender. Discrimination on the basis of women's expected roles in families accounts for a significant share of gender discrimination in education, work, the political sphere, and elsewhere. While the share of countries explicitly limiting women's rights once they marry or have children has declined, discriminatory practices continue. For example, in Spain, a top airline came under scrutiny in 2017 for requiring female job applicants to take pregnancy tests; ${ }^{79}$ in Honduras, female factory workers have reported similar requirements to obtain or keep their jobs, ${ }^{80}$ as have students simply looking to finish their secondary or tertiary education in the Philippines, Tanzania, the U.K., and the U.S. ${ }^{81}$ A 2018 survey of U.K. private-sector employers revealed that onethird believed it was reasonable to ask a woman during the hiring process about her plans to have children; $59 \%$ thought a female applicant should have to disclose a pregnancy, while $46 \%$ thought they should be able to ask whether the woman had young children. ${ }^{82}$

These forms of discrimination remain under-addressed in constitutions. Furthermore, courts have not always found that pregnancy discrimination is fully encompassed by existing protections against sex discrimination..$^{{ }_{3}}$ These gaps in protections widen further when taking into account many constitutions' limited application to private employers and schools, as explored earlier in the case of Enita Mandizvidza in Zimbabwe.

Overall, just $6 \%$ of constitutions include pregnancy as a prohibited ground for discrimination. For example, Fiji's constitution states: "A person must not be unfairly discriminated against, directly or indirectly on the grounds of his or her ... sex, gender ... marital status or pregnancy." ${ }^{84}$ Bolivia's constitution provides: "The State prohibits and punishes all forms of discrimination based on sex ... [and] pregnancy." ${ }^{85}$ Spain's constitution guarantees that "[t]he public authorities ... ensure full protection of . . mothers, whatever their marital status." ${ }^{\text {" } 6}$

Reproductive-age married women are often subject to discrimination because of their anticipated likelihood of pregnancy and caregiving. At least $8 \%$ of countries address equality and nondiscrimination based on marital or civil status. For example, Malawi's constitution states: "Women have the right to full and equal protection by the law, and have the right not to be discriminated against on the 
basis of their gender or marital status." ${ }^{87}$ In other countries, marital or civil status is commonly included in overall equal rights provisions alongside other prohibited grounds of discrimination.

Finally, some countries include language actively promoting the sharing of responsibilities between parents. Since the presumption that women will be the primary caregivers contributes to discrimination against women in the workplace and men in family roles, this language represents an important step toward shifting norms toward equal opportunities at work and at home for both parents. Ecuador's constitution, for instance, provides that citizens' duty “to help feed, educate, and raise one's children" is a "joint responsibility of mothers and fathers, in equal proportion." ${ }^{88}$ Similarly, Colombia's constitution provides: "The state shall promote the joint responsibility of both mother and father, and shall monitor fulfillment of the mutual duties and rights between mothers, fathers, and children." ${ }_{9}$

It is important to recognize that women continue to play disproportionate roles in caregiving globally, and to identify how their greater time investment in caring for children or older family members can lead to direct and indirect discrimination. However, laws reinforcing the idea that caregiving is primarily women's responsibility only further entrench this inequality, even when targeting women as beneficiaries. Three cases spanning the past 40 years - two from Germany and one from South Africa-illustrate some of the ways that courts have navigated this balance.

\section{Germany: Legal Approaches to Advancing Gender Equality at Home}

In Germany, a 1979 case followed a decade of legal reforms and cases designed to shift norms around roles within the family. Most notably, in 1976, the Parliament reformed the Civil Code, eliminating a provision that had clearly delineated men's responsibility to earn income and women's responsibility to manage housework. ${ }^{\circ \circ}$ Three years later, the Constitutional Court declared that a law providing women working outside the home with one paid "holiday" each month to do housework was unconstitutional, in that men were not offered the same benefit. ${ }^{91}$ In so doing, the Court helped dismantle the expectation that women alone were responsible for household upkeep.

In 2011, the Court heard a challenge to a law relevant to family caregiving. In the intervening years, the constitution's equality provision had been amended to add language specifically mandating that the government take steps to realize gender equality in practice: "Men and women shall have equal rights. The state shall promote the actual implementation of equal rights for women and men and take steps to eliminate disadvantages that now exist." ${ }^{22}$ In the case, a woman who had recently given birth contested the structure of Germany's paid parental leave program, which offered each family 12 months of leave, along with two "bonus" months if the father took at least two months of the total leave available. In other countries that have adopted such incentive structures for their paid leave policies, 
the share of men taking leave has increased, an important step toward shifting restrictive gender norms around both work and caregiving. ${ }^{93}$ The same was true in Germany: between the adoption of the provision in 2007 and the end of 2009, the share of fathers taking leave grew from $15 \%$ to $24 \% .{ }^{94}$

However, the woman challenging the policy argued that she was uniquely equipped to provide care for her baby, who had been born prematurely, and that therefore she should be able to take both the 12 months available to her and the two "bonus" months reserved for couples sharing leave. ${ }^{95}$ Nevertheless, the Court reasoned that fathers still faced significant stigma in taking leave, and that invalidating the policy would undermine the constitution's protections of substantive gender equality. Finding that it had a "constitutional duty . . . to enforce gender equality in social reality and overcome traditional gender roles in the future," the Court dismissed the woman's challenge and maintained the policy's incentive structure. ${ }^{96}$

\section{South Africa: When a Ruling Benefiting Women Nevertheless Reinforces Stereotypes}

A contrasting decision comes from South Africa. In 1994, President Nelson Mandela issued an order to pardon all incarcerated mothers, but not fathers, with children under 12. In 1996, John Hugo, an incarcerated single father with a 12-year-old son, challenged the order as unconstitutional gender-based discrimination. The lower courts ruled in Hugo's favor, finding that the "pardon was based on the impermissible stereotype that mothers are the primary caretakers of children." 97

However, the Constitutional Court reversed in 1997, finding that the order did not amount to "unfair discrimination," given that women did in fact typically play a larger role in caregiving than men, and citing the pardon's widespread benefits for the nation's children..$^{98}$ Consequently, although the decision acknowledged the social reality of women's disproportionate role in childcare, it also arguably reinforced gender stereotypes that have long inhibited men's participation at home and women's participation at work and in the public sphere. In the Court's view, however, the use of a generalization to benefit a group did not raise the same concerns as a generalization used to harm. ${ }^{99}$

\section{Affirmative Measures and "Unfair" Discrimination in Constitutions}

Designing constitutions to fully protect gender equality will require language enabling governments to undertake positive action to remedy the persisting impacts of past discrimination. In chapter 2, we explored the case for affirmative measures, and the importance of constitutional language ensuring that policies that take into account the impacts of past racial/ethnic discrimination are not automatically considered equal rights violations. Given women's long-standing exclusion from institutions and positions of power, affirmative measures are also important for gender equality. 
Some countries have approached issues of substantive equality through language regarding "fairness." While potentially allowing for affirmative steps, evaluations of what's "fair" inevitably raise difficult questions. Prohibiting only "unfair" discrimination, which allows courts to distinguish between actions that unjustly disadvantage a group and actions designed to advance equality in practice, provides one constitutional approach to affirmative measures. Yet it also may open the door to discrimination.

The term "unfair discrimination" appears in several constitutions adopted over the past 25 years. Like South Africa (1996), Zimbabwe (2013) and Fiji (2013) guarantee protection from unfair discrimination, further clarifying that discrimination is presumed "unfair" until established otherwise. Similarly, Albania (1998) prohibits "unjust" discrimination, while Finland (1999) prohibits discrimination "without an acceptable reason." An additional $8 \%$ of countries have provisions explicitly allowing for any "restriction . . . or . . . any privilege or advantage that, having regard to its nature and to special circumstances pertaining to those persons or to persons of any other such description, is reasonably justifiable in a democratic society."

For gender, questions of what's "unfair" commonly intersect with how countries address pregnancy, newborn care, and other family issues often involving both genuine biological differences and restrictive gender norms and stereotypes. ${ }^{100}$ As demonstrated throughout this chapter, many countries maintain laws and policies that reinforce specific gender roles in public and private life-and ultimately, while judges aim for objectivity, they are influenced by their own countries' norms, as well as their personal beliefs and experiences. Women also remain significantly underrepresented on the highest courts around the world. ${ }^{101}$ Against this backdrop, tasking courts with applying a vague, inherently subjective standard of "unfair discrimination" could open the door to laws or decisions that are either directly discriminatory and disadvantage large groups of women or, as demonstrated in Hugo, benefit some women, but in a way that undermines gender equality more broadly. This risk is greatest in the absence of explicit prohibitions of discrimination on the basis of pregnancy, marital, and family status.

\section{Addressing Gender Equality Loopholes: Constitutional Exceptions for Religious and Customary Law}

A final way that constitutions can shape equal rights regardless of gender, and specifically equal rights within the family, is their treatment of religious and customary law, which are often invoked to argue against equality in families and reproductive health. Some constitutions explicitly provide that religious and customary laws can take precedence over the constitution with regard to family matters including marriage, divorce, and inheritance. In defending primacy of religious or customary law, proponents cite religious freedom (addressed in chapter 5) and the right of national self-determination. 
Yet CEDAW (ratified by 189 countries) and other global treaties and agreements-concluded by leaders from every world region with representation from across religions, belief systems, and nonbeliefs-are clear that the equal rights of women and girls should take legal precedence over discriminatory customary or religious practices. ${ }^{102}$ More recently, UNESCO, which has 193 member states, adopted the Universal Declaration on Cultural Diversity, which proclaims: "No one may invoke cultural diversity to infringe upon human rights guaranteed by international law, nor limit their scope." ${ }^{103}$

Regional agreements and courts have similarly concluded that equal rights across sex and gender should take precedence over customary or religious laws. For example, the Protocol to the African Charter on Human and Peoples' Rights on the Rights of Women in Africa, commonly known as the Maputo Protocol, provides comprehensive protections for women's rights in the family, including equal rights in marriage, divorce, and inheritance. ${ }^{104}$ As of March 2019, 36 African countries had ratified the protocol, while another 15 had signed; just three had neither signed nor ratified. ${ }^{105}$ In 2018, the African Court on Human and Peoples' Rights (AfCHPR) applied the Maputo Protocol in a case addressing Mali's Persons and Family Code, which allowed girls to be married at 16 (or 15 with her father's consent), and established religious and customary law as the default inheritance regime, providing women with only half the inheritance of men. ${ }^{106}$ Ruling that both religious and customary provisions directly violated the protocol, the Court ordered the legislature to amend the law.

Similarly, in Europe, regional laws binding all E.U. members-including the Equal Treatment Directive of 2000, the Gender Equality Directive of 2006, and the European Convention on Human Rights (ECHR)-clearly establish that equal rights take precedence over discriminatory religious laws or practices, or discriminatory applications of religious law. This principle has had important implications for gender equality as well as discrimination on other grounds. For example, in 2018, the European Court of Human Rights ruled that a Greek court had violated the ECHR's protections against discrimination by applying Islamic law to an inheritance case involving Molla Sali, a Muslim widow. ${ }^{107}$ Sali's late husband had written up his will according to Greek civil law; nevertheless, after the man's sisters challenged the will's validity, the Greek court applied Islamic law, leaving Sali with a fraction of the inheritance she was entitled to (or intended by her husband). ${ }^{108}$

These global and regional agreements align with the broader principle that the arbitrary circumstances of one's birth-including gender and geography-should have no bearing on the applicability of universal rights. Yet the realization of this principle, and the global commitments it reflects, requires its enshrinement within enforceable domestic laws. As of this writing, in $8 \%$ of countries, including $17 \%$ in sub-Saharan Africa, 13\% in East Asia and the Pacific, 10\% in the Middle East and North Africa, and $12 \%$ in South Asia, customary and religious laws are explicitly 
permitted to prevail over all or some constitutional equality provisions. What are the impacts of these provisions, and how have courts and activists successfully changed laws permitting discrimination?

\section{Zimbabwe: Reforming the Constitution to Strengthen Women's Rights}

A 1999 case from Zimbabwe's Supreme Court provides an example of what is at risk when customary or religious practices are constitutionally privileged over women's equal rights-as well as the potential for reform.

When Venia Magaya's father died, a community court ruled that she should inherit, as she was his oldest surviving child. But when her younger half-brother appealed the decision based on customary law, Venia lost her right to the family home where she lived; her brother kicked her out, leaving her to live in a shack. Venia appealed, but the Supreme Court upheld the decision, finding that discrimination against women under customary law was "the nature of African society" and did not violate the constitution. ${ }^{109}$ Under Article 23 of the constitution at the time, gender discrimination was prohibited, but the text explicitly provided for exceptions in cases of customary law. ${ }^{110}$ Following the Court's ruling, women marched through the streets of Harare, hoisting signs with slogans including "We will not accept customary legalised tyranny" and "Discrimination against women is not compulsory in African society."

That same year, women's advocacy groups built alliances with civil society organizations nationwide during Zimbabwe's constitution drafting process. Although the draft constitution included a gender equality guarantee, the groups collectively felt the drafting process had not been transparent or inclusive, and consequently campaigned against it in the 2000 constitutional referendum. The new constitution was rejected in a $54 \%$ to $46 \%$ vote, with a voter turnout rate of $26 \% .{ }^{112} \mathrm{~A}$ decade later, however, as another constitution drafting process commenced, the women's groups organized a lobbying group for advancing their rights. ${ }^{113}$ Dubbed the "G-20," the group undertook a "gender audit" of the draft constitution and compiled a list of demands for "the prohibition of unfair discrimination, the recognition of women as equal citizens, a Bill of Rights to supersede the customary law, and the protection of women from all forms of violence."114

The resulting constitution included strong protections of women's rights and called for the establishment of a "Gender Commission" charged with "do[ing] everything necessary to promote gender equality," including reviewing discriminatory laws and recommending changes. ${ }^{115}$ The 2013 constitution also maintained a "right to culture," which has its own basis in global agreements, and can provide indigenous and marginalized groups an important tool for preserving their languages and traditions. ${ }^{116}$ However, as the G-20 had demanded-and as countries have ratified in global treaties - the "right to culture" provision made clear that gender equality would take precedence, by establishing that "no person exercising these rights may do so in a way that is inconsistent with" the constitution's 
fundamental rights. As Zimbabwe's example demonstrates, reforming discriminatory customary laws may ultimately require a multipronged strategy that centers on community engagement and leverages the courts, international human rights agreements, and constitutional reform. ${ }^{117}$

\section{South Africa: Ensuring Gender Equality Takes Precedence over Discriminatory Customary Laws}

In South Africa, the 1996 constitution included strong protections for gender and racial equality; at the same time, the constitution recognized the country's legal pluralism and gave limited constitutional recognition to customary law. ${ }^{118}$ The constitution also obliges courts to "promote the spirit, purport and objects of the Bill of Rights" when "interpreting" or "developing" customary law, ${ }^{119}$ signaling their capacity to change customary law in conformance with constitutional values through their rulings. In a 2004 case, the Constitutional Court put these provisions into practice to determine whether two customary laws governing inheritance were compatible with the equality guarantee. ${ }^{120}$

Before the Court were two questions: first, the constitutionality of Section 23 of the Black Administration Act, which established that customary law rather than the Intestate Act would apply to black South Africans' estates; and second, the constitutionality of primogeniture in the context of customary law, a principle by which only male descendants qualify as heirs for individuals who die without a will.

Addressing the first question, the Court quickly determined that a separate legal system for black South Africans' estates was inherently discriminatory, thus violating the equality article. Turning to the question of primogeniture, the Court first acknowledged that historically the male heir was expected to live with and financially support the deceased's entire family; thus, the benefits of the inheritance law ostensibly extended to all descendants. However, the Court explained, "customary law has not kept pace" with societal values and circumstances, including nuclear family-centered living arrangements. ${ }^{121}$ According to the Court, " $[\mathrm{t}]$ rue customary law will be that which recognises and acknowledges the changes which continually take place." ${ }_{122}$

Discussing remedies, the Court acknowledged its constitutional responsibility to consider whether the customary-law rules of succession could be modified to align with the Bill of Rights. ${ }^{123}$ However, given its discriminatory effects for women, the Court found that the customary law could not "be reconciled with the current notions of equality and human dignity as contained in the Bill of Rights," 124 and was therefore invalid. In other words, while the Court carefully considered the customary law and aimed to interpret it as progressively as possible-thus engaging in a sincere effort to reconcile the country's parallel legal traditions-the constitution's strong, superseding protections for equality ultimately prevailed. 


\section{Moving Forward: Women's Role in Reforming Laws}

Women in many countries are directly advocating for clear constitutional protections against religious and cultural practices that harm women and girls, along with strong commitments to implementation and community engagement. Just as the Bill of Rights' supremacy was a core demand of the women's groups that shaped the 2013 Zimbabwe constitution, Somalia's 2012 provisional constitution, in addition to guaranteeing gender equality, explicitly bans female genital mutilation, describing it as "a cruel and degrading customary practice . . . tantamount to torture." ${ }^{125}$

Women have also been directly involved in reforming customary law and practices. As many scholars and activists have emphasized, customary law was historically an unwritten, flexible, and evolving form of law; only when a limited version of customary law was codified following colonialism, often with the input of only a few male elders and colonial officials, did it become static and increasingly antiquated. ${ }^{226}$ According to constitutional scholar Muno Ndulo, urging the courts to restore the understanding that customary law is flexible and progressively interpret customary law in accordance with contemporary norms of equality-coupled with the adoption of strong constitutional equality provisions-may be an effective strategy for accelerating change. ${ }^{127}$ In Liberia, where the constitution contains an unconditional gender equality guarantee, the legal system has been used to empower individual women to shape and change their communities' customary laws. ${ }^{128}$ As these examples indicate, social movements that propel change and constitutional and legal reforms that create the national foundations for gender equality are together yielding transformative advances.

\section{Text and Interpretation}

Without a doubt, courts should do their best to rule in a way that advances substantive equality for all people regardless of sex or gender. This must mean acknowledging how laws and policies affect different groups differently. It must mean taking an expansive approach to "sex" that encompasses stereotypes and gendered expectations. However, it does not mean basing rulings on preconceived notions about the societal roles of men, women, and gender minorities.

Constitutional language can be improved to provide a strong foundation for addressing these issues. Still, even well-written constitutional provisions can fall short of their drafters' vision depending on courts' interpretations. Ultimately, working to advance both norm change and legal change is essential, and the two will inevitably influence each other. ${ }^{129}$

\section{UNFINISHED BUSINESS}

Remarkable global progress on gender equality in the past century is reflected in constitutional change. Ninety-one percent of constitutions enacted in the 1980s, 
$93 \%$ in the 1990 s, and $100 \%$ since 2000 explicitly guarantee sex and/or gender equality, compared to only $54 \%$ of those enacted before 1970 . However, the $15 \%$ of constitutions that fail to guarantee either sex or gender equality, and the $8 \%$ that allow customary or religious law to take precedence over women's equal rights, signal there is much work left to be done. Further, five constitutions use language articulating women's rights only in relation to men's, and this may not protect men from gender discrimination. Another 14 use binary language that may exclude sex and gender minorities from full constitutional protection.

Globally, one reason for optimism is women's and gender minorities' increasing role in constitutional drafting processes, which in turn is shaping these fundamental documents' approaches to gender equality. For example, $88 \%$ of constitutions in sub-Saharan Africa have been rewritten since 1990, with women often playing key roles in shaping constitutional approaches to issues such as land rights, women's political representation, violence against women, and the status of customary law. ${ }^{130}$ In Uganda, as the Constitutional Commission prepared to draft a new constitution in the early 1990s, women's groups weighed in more than any other sector of society, despite the fact that women comprised just 19\% of the 1993 Ugandan constituent assembly. ${ }^{131}$ The resulting document included powerful protections for women's rights, including equal rights in the family, affirmative measures promoting political representation, and the prohibition of harmful religious and customary practices.

Yet there are also cautionary tales. While inviting public feedback and participation in drafting may lead to more inclusive constitutional protections, submitting basic equal rights to a vote undermines the fundamental premise that these rights are already universal. More participatory mechanisms can effectively strengthen rights when they serve to include the voices and perspectives of large groups that have been historically excluded, such as women. However, participatory decisionmaking does not automatically lead to more expansive rights for groups that have been discriminated against and yet comprise small fractions of the population, which speaks to the broader need for processes that ensure the rights of minorities and subgroups.

Even the rights of large groups do not necessarily pass a vote. The recent example of the Bahamas illustrates this point. In March 2016, the Bahamian parliament's lower house voted to advance four amendments to its 1973 constitution to create stronger protections for women's rights. In addition to adding "sex" to the constitution's antidiscrimination provision, the reforms would establish that women have the same rights as men to confer citizenship. Remarking on the amendments, Prime Minister Perry Christie declared it to be a "moral imperative of the first magnitude that we seize the opportunity to usher in a new era in our civilizationan era that will proceed on the righteous and unassailable premise that we are all equal before the law irrespective of whether we are male or female."132

In June 2016, however, when presented to the public in a constitutional referendum, all four amendments failed to pass. ${ }^{133}$ According to media coverage, concerns 
that the amendment to establish gender equality would open the door to same-sex marriage drove much of the opposition. ${ }^{134}$ Prime Minister Christie even addressed these concerns directly by condemning marriage equality and reassuring voters that he "would not be supporting [the amendment] if it would change marriage in The Bahamas." ${ }^{35}$ As this example illustrates, struggles for equality across groups are often connected, and leaving any group's fundamental rights up to public debate can lead to injustice.

Moving forward across countries will require social movements that seek to both strengthen legal rights and change the restrictive gender norms that limit opportunities for women, men, and gender minorities. In some countries, norms have already shifted significantly toward equality, but the constitution and other laws have not caught up. In others, grassroots movements to change norms and public opinion will likely play pivotal roles in strengthening the prospects for legislative and constitutional reform.

Further, even in countries with relatively strong constitutional provisions, more comprehensive protections addressing discrimination based on pregnancy, marital, and family status would provide stronger foundations for women's equality. More broadly, addressing indirect gender-based discrimination is crucial. Job requirements like a minimum height often disproportionately exclude women without being essential to effective performance in the position. Similarly, mandatory work meetings unnecessarily scheduled in the evening may contribute to indirect discrimination against women where safety, societal constraints, and/or disproportionate caregiving responsibilities prevent them from attending. Finally, addressing both sex and gender discrimination would more thoroughly guard against the range of ways that bias and stereotypes limit individuals' potential.

Over the past 50 years, equal rights on the basis of sex and gender have dramatically increased in constitutions. Nevertheless, the extensive inequality that persists in the law, and the well-documented discrimination that continues to obstruct equal rights in education, work, and politics, underscore how far we have to go. In the coming decades, individuals, civil society groups, lawyers, and judges all have critical roles to play in closing gaps in the law, speaking out against gender discrimination wherever it occurs, and fulfilling gender equality not just in theory but in practice. 